KINDERGARTEN: Journal of Islamic Early Childhood Education

Homepage: bttp:// ejournal.uin-suska.ac.id/index.php/KINDERGARTEN

Vol. 2, No. 2 November 2019, Hal. 149-

Email:jcie.piand@,uin-suska.ac.id

p-ISSN 2621-0339

e-ISSN 2621-0770

\title{
Penggunaan Media Buku Cerita Bergambar dalam Perkembangan Bahasa Anak
}

\author{
Widya Anggraini Selian ${ }^{1}$, Nurhayati ${ }^{2}$, Sariah ${ }^{3}$ \\ Universitas Islam Negeri Sultan Syarif Kasim Riau \\ anggrainiwidya530@gmail.com',nurhayati.sudirman@uin_suska.ac.id \\ sariah@uin-suska.ac.id
}

\begin{abstract}
This research was instigated by some problems of student language development, so it aimed at knowing the effect of using Story Book with Picture media toward student language development at Group B of Mayang Kindergarten Pekanbaru. It was conducted from June to October 2019 at Mayang Kindergarten Pekanbaru. The subjects of this research were the students. There were two classes that were studied by the researcher-15 students of group B2 as the experimental group and 16 students of group B3 as the control group, and they were 31 students. The object was the effect of using Story Book with Picture media toward student language development at Group B of Mayang Kindergarten Pekanbaru. Observation, documentation, and interview were the techniques of collecting the data. Based on the research findings, the use of Story Book with Picture media could affect student language development, and it was based on the comparison between pretest and posttest of experimental group using t-test. It was obtained that tobserved was 20.051, and Sig. (2-tailed) 0.000. Because Sig. (2-tailed) was lower than 0.05, it could be concluded that there was a significant effect after using Story Book with Picture media toward student language development. So, it meant that $H_{0}$ was rejected and $H_{a}$ was accepted. There was an effect before and after using Story Book with Picture media toward student language development of experimental group. The effect of using Story Book with Picture media toward student language development at Group B of Mayang Kindergarten Pekanbaru was $66,76 \%$.
\end{abstract}

Keywords: Story Book with Picture Media Use, Language Development 


\begin{abstract}
ABSTRAK
Penelitian ini dilatarbelakangi dengan adanya beberapa permasalahan perkembangan bahasa anak sehingga penelitian ini bertujuan untuk mengetahui Pengaruh Penggunaan Media Buku Cerita Bergambar terhadap Perkembangan Bahasa Anak Kelompok B di Taman Kanakkanak Mayang Pekanbaru. Penelitian ini dilakukan pada bulan JuniOktober 2019 bertempat di TK Mayang Kota Pekanbaru. Subjek penelitian ini adalah Murid-murid di TK Mayang Kota Pekanbaru, terdiri dari dua kelas yang akan diteliti oleh peneliti yaitu B2 sebagai kelas eksperimen berjumlah 15 murid dan B3 sebagai kelas kontrol berjumlah 16 murid, jumlah keseluruhan 31 murid, sedangkan objek penelitian ini adalah Pengaruh Penggunaan Media Buku Cerita Bergambar Terhadap Perkembangan Bahasa Anak Kelompok B di Taman Kanak-kanak Mayang Pekanbaru. Teknik pengumpulan data yang digunakan oleh penulis adalah observasi, dokumentasi, dan wawancara. Berdasarkan hasil penelitian yang dilakukan di TK Mayang Pekanbaru bahwa pengaruh penggunaan media buku cerita bergambar dapat mempengaruhi perkembangan bahasa anak dengan data pada perbandingan pretest dan posttest kelas eksperimen dengan menggunakan uji-t maka diperoleh $t_{\text {hitung }}=20,051$ dan Sig. $(2$-tailed $)=$ 0.000. Karena Sig. (2-tailed) $=0.000<0,05$ maka dapat disimpulkan bahwa terdapat pengaruh yang signifikan setelah menggunakan media buku cerita bergambar terhadap perkembangan bahasa anak. Jadi artinya Ho ditolak dan $\mathrm{Ha}$ diterima yang berarti dalam penelitian ini terdapat pengaruh penggunaan media buku cerita sebelum dan sesudah terhadap perkembangan bahasa anak yang berada pada kelas eksperimen. Pengaruh penggunaan media buku cerita terhadap perkembangan bahasa anak kelompok B di TK Mayang Pekanbaru sebesar $66,76 \%$.
\end{abstract}

Kata kunci : Penggunaan Media Buku Cerita Bergambar, Perkembangan Bahasa

\title{
PENDAHULUAN
}

Proses perkembangan manusia utuh dimulai sejak janin dalam kandungan ibunya dan memasuki usia emas (golden age) sampai usia enam tahun. Usia 0 sampai 6 tahun, merupakan masa peka bagi anak sehingga para ahli menyebutnya The Golden Age. Karena perkembangan kecerdasannya mengalami peningkatan yang sangat signifikan. Usia dini atau prasekolah merupakan usia emas bagi anak untuk belajar. Oleh karena itu, kesempatan ini hendaknya dimanfaatkan sebaik-baiknya untuk pembelajaran anak karena rasa ingin tahu anak usia ini berada di posisi puncak. 
Anak usia dini adalah individu yang sedang mengalami proses pertumbuhan dan perkembangan yang sangat pesat, bahkan dikatakan sebagai lompatan perkembangan. Anak usia dini memiliki rentang usia yang sangat berharga dibanding usia-usia selanjutnya karena perkembangan kecerdasannya sangat luar biasa. Usia tersebut merupakan fase kehidupan yang unik, dan berada pada masa proses perubahan berupa pertumbuhan, perkembangan, pematangan, dan penyempurnaan, baik pada aspek jasmani maupun rohaninya yang berlangsung seumur hidup, bertahap, dan berkesinambungan.

Usia dini merupakan usia dimana anak mengalami pertumbuhan dan perkembangan yang pesat. Usia dini disebut sebagai usia emas (golden age), maka peran stimulasi berupa penyediaan lingkungan yang kondusif harus disiapkan oleh para pendidik, baik orang tua, guru, pengasuh ataupun orang dewasa lain yang ada di sekitar anak, sehingga anak memiliki kesempatan untuk mengembangkan seluruh potensinya. Potensi yang dimaksud meliputi aspek moral dan nilai agama, sosial, emosional dan kemandirian, kemampuan bahasa, kognitif, fisik motorik, dan seni.

Salah satu perkembangan yang penting bagi anak yaitu aspek bahasa. Bahasa merupakan media berkomunikasi dengan orang lain. Tercakup semua cara untuk berkomunikasi. Fikiran dan perasaan dinyatakan dalam bentuk lambang atau simbol untuk mengungkapkan suatu pengertian, seperti dengan menggunakan lisan, tulisan, isyarat, bilangan, lukisan, dan mimik muka. Bahasa sebagai alat komunikasi memungkinkan dua individu atau lebih mengekspresikan berbagai ide, arti, perasaan dan pengalaman. Di dalam Alqur'an pun sudah digambarkan bahwa kemampuan manusia untuk berbahasa merupakan kemampuan yang membuat manusia memiliki kelebihan dibanding dengan makhluk Allah SWT yang lainnya, termasuk Malaikat.

Dalam surah al-baqarah ayat 31 Allah SWT. berfirman:

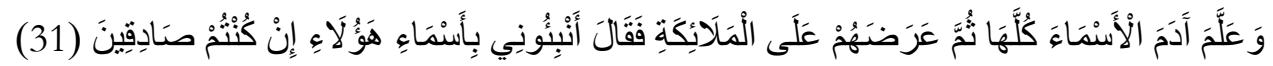

31. Dan Dia mengajarkan kepada Adam nama-nama (benda-benda) selurubnya, kemudian mengemukakannya kepada para Malaikat lalu berfirman : "Sebutkanlah kepada-Ku nama benda-benda itu jika kamu mamang benar orang-orang yang benar!"

Dan diajarkannya kepada Adam nama-nama maksudnya nama-nama benda kesemuanya dengan jalan memasukkan kedalam kalbunya pengetahuan tentang 
benda-benda itu, kemudian dikemukakan oleh mereka maksudnya benda-benda tadi yang ternyata bukan saja benda-benda mati, tetapi juga makhluk-makhluk berakal. kepada para malaikat lalu Allah berfirman bahwa tidak ada yang lebih tahu daripada kamu antara makhluk-makhluk yang kuciptakan atau bahwa kamulah yang lebih berhak untuk menjadi khalifah.

Bahasa memegang peranan yang sangat penting dalam kehidupan anak, sebab melalaui bahasa anak dapat berkomunikasi dengan lingkungan sekitarnya, dan mengungkapkan gagasan atau pikiran pada orang lain. Bahasa juga memberikan pengaruh yang besar dalam perkembangan anak. Dengan bahasa anak tumbuh berkembang menjadi manusia yang mampu bersosialisasi di tengah-tengah masyarakat.

Untuk mengembangkan bahasa pada anak memerlukan metode yang tepat, salah satunya adalah metode bercerita. Metode bercerita adalah metode yang banyak digunakan di taman kanak-kanak. Metode ini merupakan salah satu strategi pembelajaran yang dapat memberikan pengalaman belajar bagi anak TK. Cerita yang kita bawa untuk anak harus menarik dan mengundang perhatian anak agar tidak lepas dari tujuan pendidik bagi anak TK. Untuk mendukung metode bercerita ini kita memerlukan media, salah satu media yang tepat adalah menggunakan media buku cerita bergambar.

Media buku cerita bergambar adalah buku bergambar tetapi dalam bentuk cerita, bukan buku informasi. Dengan demikian buku bergambar sesuai dengan ciriciri buku cerita, mempunyai unsur-unsur cerita (tokoh, plot, alur). Salah satu kegiatan yang dapat dilakukan oleh guru dengan media buku cerita bergambar adalah bercerita. Dengan menggunakan media ini, maka pembelajaran bagi anak diharapkan dapat menjadi efektif terutama dalam mengembangkan aspek bahasa pada anak.

\section{METODE}

\section{Desain Penelitian}

Berdasarkan permasalahan yang dikemukakan sebelumnya dan tujuan yang ingin dicapai, maka jenis penelitian ini adalah Quasi eksperiment. Dimana, 
penelitian Quasi eksperiment ini merupakan suatu penelitian eksperimen semu, yang variabel-variabelnya tidak dikontrol sepenuhnya.

Di dalam desain ini observasi dilakukan sebanyak dua kali yaitu sebelum eksperimen dan sesudah eksperimen. Observasi yang dilakukan sebelum eksperimen $\left(0_{1}\right)$ disebut pre-test, dan observasi sesudah eksperimen $\left(0_{2}\right)$ disebut post-test

\begin{tabular}{cccc}
\hline Kelompok & Pretest & Perlakuan (X) & Posttest \\
$\mathrm{KK}$ & $\mathrm{O}_{1}$ & $\mathrm{X}_{1}$ & $\mathrm{O}_{1}$ \\
$\mathrm{KE}$ & $\mathrm{O}_{2}$ & $\mathrm{X}_{2}$ & $\mathrm{O}_{2}$ \\
\hline
\end{tabular}

Keterangan:

KK : Kelompok Kontrol

$\mathrm{KE}$ : Kelompok Eksperimen

$\mathrm{O}_{1}$ : Pre-Test (untuk kelompok control)

$\mathrm{O}_{1} \quad$ : Pre-Test (untuk kelompok eksperimen)

$\mathrm{O}_{2} \quad$ : Post-Test (untuk kelompok control)

$\mathrm{O}_{1} \quad$ : g Post-Test (untuk kelompok eksperimen)

$\mathrm{X}_{1} \quad$ : Pengembangan bahasa dengan metode bercerita biasa

$\mathrm{X}_{2}$ : Pengembangan bahasa dengan metode bercerita dengan media Buku Cerita Bergambar

\section{Lokasi dan Waktu Penelitian}

Penelitian ini dilakukan di Taman Kanak-kanak Mayang Kecamatan Tampan Pekanbaru. Penelitian dilakukan pada bulan Juni sampai bulan Agustus 2019, yang didahului dengan uji coba instrument di TK Mayang.

\section{Subjek dan Objek Penelitian}

Subjek dalam penelitian ini adalah Anak-anak TK Mayang Kecamatan Tampan Pekanbaru berjumlah 61 anak, sedangkan yang menjadi objek penelitian ini adalah pengaruh penggunaan media buku cerita bergambar terhadap perkembangan bahasa anak. Penelitian ini terdiri dari dua variabel yaitu Buku Cerita Bergambar (variabel X) dan Perkembangan Bahasa (variabel Y)

\section{Populasi dan Sampel}

Populasi adalah wilayah generalisasi yang terdiri dari objek atau subjek yang mempunyai kualitas dan karakteristik tertentu yang diterapkan oleh peneliti 
untuk dipelajari dan kemudian ditarik kesimpulannya. Populasi dalam penelitian ini adalah anak-anak kelompok B TK Mayang Pekanbaru, terdiri dari 4 kelas yaitu berjumlah 61 anak.

\section{Teknik Pengumpulan Data}

Teknik pengumpulan data yang penulis gunakan dalam penelitian ini ada 4 yaitu sebagai berikut:

a. Observasi

Observasi adalah melakukan pengamatan dan pencatatan suatu objek, secara sistematis fenomena yang diselidiki. Dari penelitian ini, penulis akan mengobservasi anak ketika sedang mengikuti pelajaran yang diberikan oleh guru dengan menggunakan media buku cerita bergambar juga ketika anak berinteraksi dengan lingkungan di sekolahnya. Pengamatan ini dilakukan dengan lembar obvervasi yang diisi dengan tanda chek list $(\sqrt{ })$ atau $\mathrm{BB}, \mathrm{MB}$, BSH, BSB pada kolom yang sesuai dengan hasil pengematan. Lembar observasi ini dijadikan pedoman oleh penulis agar saat melakukan observasi lebh terarah, terukur sehingga hasil data yang telah didapatkan mudah untuk diolah.

b. Tes

Tes merupakan rangkaian pertanyaan yang memerlukan jawaban sebagai alat ukur dalam proses asesmen. Tes juga digunakan untuk mengukur tingkat pencapaian keberhasilan siswa setelah melakukan belajar.

c. Wawancara

Dari penelitian ini, penulis akan mewawancara ringan dengan guru, penulis akan melakukan tanya jawab kepada guru dengan berdialog untuk mengetahui sejauh mana perkembangan bahasa pada anak.

d. Dokumentasi

Dari penelitian ini akan diambil data dari sekolah yang peneliti teliti, yaitu TK Mayang. Sejauh pengamatan awal yang penulis lakukan di TK ini terdapat 4 orang pendidik, 1 orang kepala sekolah dan 1 orang bendahara. 
Jumlah anak di kelompok B2 dan B3 berjumlah 31 orang. TK Mayang Pekanbaru.

\section{Teknik Analisis Data}

Teknik analisis data merupakan suatu proses mengklasifikasi, memberikan kode-kode tertentu, mengolah dan menafsirkan data hasil penelitian, sehingga data hasil penelitian menjadi bermakna.

Teknik analisis data yang digunakan pada penelitian ini adalah teknik analisis uji-t. Untuk melihat apakah ada pengaruh penerapan media kartu bergambar terhadap kemampuan mengenal huruf anak sebelum dan sesudah diberi perlakuan.

Adapun proses dalam analisis data ini menggunakan rumus uji-t digunakan untuk menguji signifikasikan perbedaan mean.

\section{PEMBAHASAN}

Untuk mengetahui seberapa besar hasil dari Pengaruh Penerapan media buku cerita bergambar Terhadap Perkembangan bahasa Pada Anak di TK Mayang Pekanbaru

$$
\mathrm{G}=66,76 \%
$$

Merujuk pada hasil penggunaan rumus $G$ di atas, maka dapat dilihat kategori peningkatan sebesar 66,76\% yaitu berada pada kategori tinggi 66,76\%>70\%. Jadi ketika peneliti melakukan pengamatan di TK Mayang Pekanbaru pada tahap awal observasi sebelum diberikan perlakuan ( $p$ retest) ternyata perkembangan bahasa anak di TK Mayang Pekanbaru belum berkembangan dengan baik atau tergolong masi banyak yang belum berkembang.

Setelah penerapan media buku cerita bergambar, anak memperlihatkan antusiasme ketika melakukan kegiatan meniru yang di contohkan oleh guru. Setelah anak diberikan penerapan media buku cerita bergambar dilakukan evaluasi terhadap perkembangan bahasa anak. Berikut paparan data anak setelah dilakukan posttest pada kelas eksperimen diperoleh jumlah nilai 90,83\% jika dilihat dari kriteria perorangan tidak ada anak yang berada pada kriteria $\mathrm{BB}, \mathrm{MB}$ dan $\mathrm{BSH}$.

Anak yang berada pada kriteria BSB terdapat 15 Orang anak atau 90\% Peningkatan rata-rata pada kelas eksperimen sangat terlihat pada saat pretest rata- 
ratanya $28,74 \%$ dan meningkat saat Posttest menjadi $90,83 \%$ setelah penerapan media buku cerita bergambar. Sedangkan kelas kontrol peningkatan bahasa anak tidak terlalu tinggi karena hanya melakukan metode biasa atau tanpa perlakuan, dapat dilihat dari data kelas kontrol pada pretest dengan nilai 127 dengan rata-rata 26,46\% sedangkan pada posttest diperoleh nilai 283 dengan rata-rata 57,7\%. Jika dilihat dari kriteria perorangan terdapat 8 orang atau $80 \%$ pada kriteria $\mathrm{BSH}$, pada kriteria $\mathrm{MB}$ terdapat 7 orang anak, dan tidak ada anak pada kriteria BSM, MB dan BB.

Tabel I.1

Perkembangan Bahasa Pada Anak Di Kelompok B TK Mayang Pekanbaru dalam Penggunaan Media Buku Cerita Bergambar Sebelum diberi Perlakuan (pretest)Kelas Eksperimen

\begin{tabular}{|c|c|c|c|c|}
\hline No & Kriteria & Rentang Skor & $\bar{F}$ & $\%$ \\
\hline 1 & Berkembang Sangat Baik & $76-100 \%$ & 0 & 0 \\
\hline 2 & Belum Berkembang Sesuai Harapan & $56-75 \%$ & 0 & 0 \\
\hline 3 & Mulai Berkembang & $41-45 \%$ & 1 & 6,7 \\
\hline 4 & Belum Berkembang & $<40 \%$ & 14 & 93,3 \\
\hline & Jumlah & & 15 & 100 \\
\hline
\end{tabular}

Tabel I.2.

Perkembangan Bahasa Pada Anak Kelompok B di TK Mayang Pekanbaru dalam Penggunaan Media Buku Cerita Bergambar Sesudah diberi Perlakuan (posttest) Kelas Eksperimen

\begin{tabular}{ccccc}
\hline No & Kriteria & Rentang Skor & F & $\%$ \\
\hline 1 & Berkembang Sangat Baik & $76-100 \%$ & 15 & 100 \\
2 & Belum Berkembang Sesuai Harapan & $56-75 \%$ & 0 & 0 \\
3 & Mulai Berkembang & $41-45 \%$ & 0 & 0 \\
4 & Belum Berkembang & $<40 \%$ & 0 & 0 \\
& Jumlah & 15 & 100 \\
\hline
\end{tabular}

\section{KESIMPULAN}

Berdasarkan hasil penelitian yang dilakukan di Taman Kanak-kanak Mayang Pekanbaru bahwa pengaruh penggunaan media buku cerita bergambar dapat mempengaruhi perkembangan bahasa anak dengan data pada perbandingan pretest dan posttest kelas eksperimen dengan menggunakan uji-t maka diperoleh $\mathrm{t}_{\text {hitung }}=$ 20,051 dan Sig. (2-tailed $)=0.000$. Karena Sig. $(2$-tailed $)=0.000<0,05$ maka dapat 
disimpulkan bahwa terdapat pengaruh yang signifikan setelah menggunakan media buku cerita bergambar terhadap perkembangan bahasa anak. Jadi artinya Ho ditolak dan Ha diterima yang berarti dalam penelitian ini terdapat pengaruh penggunaan media buku cerita sebelum dan sesudah terhadap perkembangan bahasa anak yang berada pada kelas eksperimen. Pengaruh penggunaan media buku cerita terhadap perkembangan bahasa anak kelompok B di TK Mayang Pekanbaru sebesar 66,76\% dari perhitungan $\mathrm{R}$ Square. Sedangkan sisanya sebesar 151\% dipengaruhi oleh variabel lain yang tidak termasuk dalam penelitian ini.

\section{REFERENSI}

Al-Qur,an Surah Al-Baqarah Ayat 31

Arikunto Suharsimi. (2010). Prosedur Penelitian Suatu Pendekatan Praktik. Jakarta: Rineka Cipta.

Arsyad Azhar. (2010). Media Pembelajaran. Jakarta: PT Raja Grafindo.

Afnida Mutia. (2016). Penggunaan Buku Cerita Bergambar dalam Pengembangan Babasa Anak Pada TK A. Volume 01. No 01.

Darwis Amri. (2014). Metode Penelitian Pendidikan Islam. Jakarta: PT Raja Grafindo Persada.

Dhieni dkk Nurbiana. (2012). Metode Pengembangan Bahasa. Jakarta: Universitas Terbuka.

Emzir. (2010). Metodologi Penelitian Pendidikan: Kuantitatif dan Kualitatif. Jakarta: Rajawali Pers.

Indahyani Tara. (2014). Penerapan Metode Bercerita Berbantuan Media Buku Bergambar Untuk Pengembangan Kemampuan Berbahasa Anak Kelompok B, e-Journal PG$P A U D$ Universitas Pendidikan Ganesha Jurusan Pendidikan Anak Usia Dini Volume 2 No 1.

Kurnia Rita. (2009). Metodologi Pengembangan Bahasa Anak Usia Dini. Pekanbaru: Cendekia Insani.

Latif dkk Mukhlar. (2013). Orientasi Baru Pendidikan Anak Usia Dini. Jakarta: Kencana Prenada Media Group.

Masitoh. Dkk. (2012). Strategi Pembelajaran TK. Tangerang Selatan: Universitas Terbuka. 
Mulyasa. (2012). Manajemen PAUD. Bandung: PT Rosda Karya.

Musfiroh Tadkiroatun. (2008). Memilih Menyusun dan Anak Usia Dini. Yogyakarta: Tiara wacana.

Nurgiyantoro Burhan. (2013). Sastra Anak Pengantar Pemahaman Dunia Anak. Yogyakarta: Gadjah Mada University Press.

Nurgiyantoro Burhan. (2015). Statistik Terapan untuk Penelitian Ilmu Sosial, Yogyakarta: Gadjah Mada University Press.

Priscilia Yosephine Putri Rosari A. A. Gede Agung Didith Pramunditya Ambara. 2014. Penerapan Metode Bercerita berbantuan Media Buku Cerita Bergambar untuk Meningkatkan Perilaku Moral. e-Journal PG PAUD Universitas Pendidikan Ganesha Jurusan Pendidikan Guru Pendidikan Anak Usia Dini (Volume 2 No. 1)

Rahayu Sri. (2017). Pengembangan Babasa pada Anak Usia Dini. Yogyakarta: Kalimedia.

Rahmawati Sri. (2018). Pengembangan Buku Cerita Bergambar Berbasis pendekatan Whole Language pada materi cerita Rakyat. Skripsi. Universitas Islam Negeri Lampung.

Sugiyono. (2010). Metode Penelitian Pendidikan. Bandung: Alfabeta.

Sunarso dan Hartono Agung. (2013). Perkembangan Peserta Didik. Jakarta: Rineka Cipta.

Syam, Suardi. (2015). Psikologi Perkembangan Peserta Didik. Pekanbaru: Zanafa.

Permendikbud RI Nomor 160 Tabun 2014.

Yuliana. (2018). Pengembangan Buku Cerita Bergambar Sebagai Bahan Ajar Dalam Perkembangan Moral Anak Usia Dini Taman Kanak-Kanak Islamiyab Desa Tanjung Raja, Skripsi, Universitas Islam Negeri Raden Intan Lampung.

Zubaidah Enny. Pengembangan Bahasa Anak Usia Dini. Yokyakarta: Universitas Negeri Yogyakarta. 